\title{
Synthesis and Characterization of Functional Nanostructured Zinc Oxide Thin Films
}

\author{
S. Shishiyanu ${ }^{\mathrm{a}}$, L. Chow ${ }^{\mathrm{b}}$, O. Lupan ${ }^{\mathrm{a}}$, and T. Shishiyanu ${ }^{\mathrm{a}}$ \\ ${ }^{a}$ Department of Microelectronics and Semiconductor Devices, Technical University of \\ Moldova, bd. Stefan cel Mare 168, MD2004 Chisinau, Republic of Moldova \\ ${ }^{\mathrm{b}}$ Department of Physics, University of Central Florida, Orlando, FL 32816-2385, U.S.A.
}

A novel aqueous relatively low-temperature thin film growth technique has been developed to fabricate a new generation of smart and functional nanostructured metal oxide thin film materials. This chemical synthetic route uses stable and inexpensive metal inorganic salts and environment-friendly solvents. The nanomaterials are obtained to analyze the physical and structural requirements of their applications in gas sensors and solar cells. The rapid photothermal processing at the $650{ }^{\circ} \mathrm{C}$ of nanostructured zinc oxide leads to the suppression of deep-defectlevel emission and improvement of near-band edge emission. The responses of the sensing elements when exposed to $100 \mathrm{ppm}$ ammonia at temperatures between $20{ }^{\circ} \mathrm{C}$ and $300{ }^{\circ} \mathrm{C}$ have been assessed.

\section{Introduction}

The synthesis and characterization of various wide band gap metal oxides nanostructures such as nanowires, nanorods, nanobelts, nanobridges and nanowalls has attracted great interest due to their size, morphology-related properties, and their emerging applications in novel functional nanodevices $(1,2)$. Recently, research and development of alternative energy technologies, such as low cost flat-panel solar cells thin film devices, and many other innovative concepts have increased. $\mathrm{ZnO}$ is an important multifunctional material which has received great attention during the last few years due to their unique applications in microelectronic and optoelectronic devices, and for self-assembled growth of three-dimensional nanoscale systems $(3,4)$. Zinc oxide having a direct band gap of $3.37 \mathrm{eV}$ and an exciton binding energy $(60 \mathrm{eV})$ higher than those of $\mathrm{ZnS}(20 \mathrm{eV})$ and $\mathrm{GaN}(21 \mathrm{eV})$, is of interest for various high tech applications, such as optical devices (1), solar cells (5), piezoelectric devices (6), varistors (7), surface acoustic wave (SAW) devices (8), and gas sensors $(9,10)$.

Zinc oxide nanostructures have the potential to significantly improve the performance and durability of certain devices used in areas of importance: energy production and homeland security. A key challenge in this research is to deposit nanostructured metal oxide thin films with consistent morphology and reproducible properties with a long-term stability. $\mathrm{ZnO}$ nanostructures have been prepared by different methods like chemical vapor deposition, vapor-liquid-solid method, thermal oxidation, reactive sputtering, solgel, and chemical deposition (1-5). Among them, chemical deposition has attracted our interest for the preparation of nanostructured thin films due to the following advantages: (a) its simplicity and low cost, (b) its capability to achieve large area coatings, (c) its low deposition temperature. These advantages result in a low cost processes that has a 
reduced environmental impact and a minimum undesirable inter-diffusion of components in multilayer structures. The chemical deposition technique is an aqueous-chemical method which involves the hydrolysis of metal ions in solutions, followed by controlled heterogeneous precipitation on a substrate. It is an emerging field of research in the nanostructured thin films area. The desirable properties of the thin film can be reached by the optimization of the process parameters and post-deposition processing technique. It allows monitoring the size of nano and microparticles, their surface morphology and arrangement on substrate. This technique allows us to generate advanced functional metal oxides nano- and micro-particulate thin films at relatively low temperature from aqueous solution.

Post-deposition annealing process is being guided largely by the requirements of defects removal and electrical conductivity in metal oxide films. Recently, lamp-based rapid photothermal processing (RPP) systems have been introduced as an alternative thermal annealing equipment solution. The properties of the metal oxide films, especially the structural and electrical ones, can be improved by proper post-deposition rapid photothermal processing. Rapid photothermal processing is based on rapid radiative heating and cooling of substrates in vacuum or in the presence of inert atmosphere. The RPP system's halogen lamps provide both heating and radiations effects due to the wider spectrum from $0.4 \mu \mathrm{m}$ to $1 \mu \mathrm{m}$. The principal difference between conventional furnace annealing (CFA) and RPP is that the photo-spectra of RPP and CFA are different (11).

In the present work, we developed a method to obtain nanostructured $\mathrm{ZnO}$ thin films by chemical deposition under ultraviolet light and we investigated the impact of RPP on their properties. We expected to obtain inexpensive nanostructured thin films for solar cells and sensors applications. ZnO-based resistive type sensors have been developed for the detection of toxic gaseous compounds important for environmental monitoring and for medical diagnostics. The responses of the sensing elements that exposed to $100 \mathrm{ppm}$ of ammonia at temperatures between $20{ }^{\circ} \mathrm{C}$ and $300{ }^{\circ} \mathrm{C}$ have been assessed.

\section{Experimental}

Chemical bath deposition (12) is a method of growing thin films on a substrate immersed in aqueous solutions containing appropriate reagents at relative low temperatures (up to $100^{\circ} \mathrm{C}$ ). The nanostructured films were deposited on Corning glass substrate using a beaker placed upon a heater during the growth process under ultraviolet (UV) light. Before the deposition, the substrates were cleaned in dilute $\mathrm{HCl}$ for $10 \mathrm{~min}$, and then rinsed in de-ionized water (DI). Afterward, the glass slides were rinsed in ethanol:acetone (1:1) mixture, then rinsed in DI, and dried in a nitrogen flux. The cleaned substrates were immersed in an aqueous solution bath for definite periods of time in order to fabricate films of desired thicknesses. Films of pure and Sn-doped $\mathrm{ZnO}$ were deposited on glass substrates from aqueous zinc-complex solution comprises a mixture of $\mathrm{ZnSO}_{4}$, $\mathrm{NH}_{4} \mathrm{OH}$, and sodium stannate. The zinc concentration of the complex solution was 0.05 and $0.1 \mathrm{M}$ respectively. The doping of $\mathrm{Sn}$ was accomplished by adding appropriate amount of sodium stannate in the aqueous solution. The freshly prepared solutions were mixed thoroughly and were kept at room temperature or at $80^{\circ} \mathrm{C}$ during the deposition for 0.1-0.3 h. The details of doped $\mathrm{ZnO}$ films deposition following similar chemical method and set-up for the photoluminescence characterization and nanostructures of the zinc oxide have been reported previously $(13,14)$. 
The effects of growth conditions on the structure of the films (composition and morphology) were studied by VEGA TS 5130MM scanning electron microscope (SEM). The composition of the metal oxide films was investigated by Energy Dispersive X-ray (EDX) spectroscopy and was used to show the presence of metal and oxygen, and determine their atomic ratio. The $\mathrm{Sn} / \mathrm{Zn}$ and $\mathrm{Zn} / \mathrm{O}$ ratios in nanostructured films were analyzed by EDX and were found to be less than that in the solution. The as-deposited $\mathrm{ZnO}$ films were RPP at $300^{\circ} \mathrm{C}-650^{\circ} \mathrm{C}$ for $15 \sim 100 \mathrm{sec}$. The optimum duration of RPP was determined as $20 \mathrm{sec}$ for $\mathrm{ZnO}$ films.

\section{Results and discussions}

Figure 1 presents the surface morphology of $\mathrm{ZnO}$ films chemically deposited (a) from $\mathrm{Zn}: \mathrm{Sn}:[\mathrm{DEN}]$ (0.05 M:1 mM:0.02 M) aqueous bath: as-grown without RPP (sample 1), and (b) from Zn:Sn:[DEN] (0.10 M:1 mM:0.01 M) (sample 2). The as-grown films nanocrystallites have a mean size of $200 \mathrm{~nm}$ and $800 \mathrm{~nm}$ respectively.

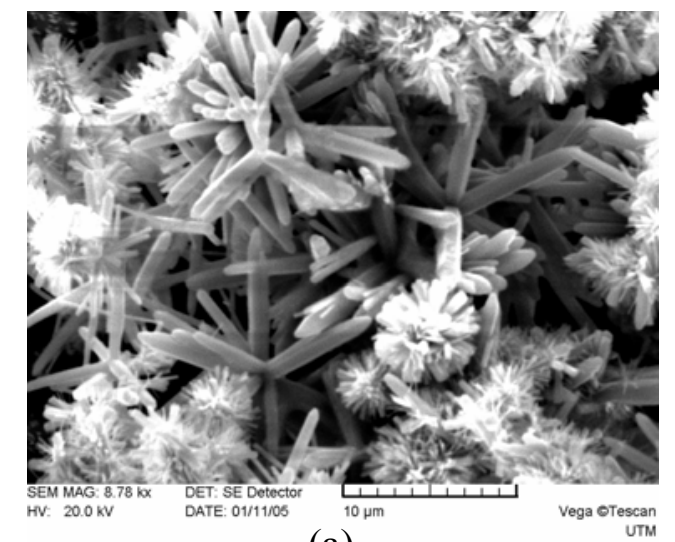

(a)

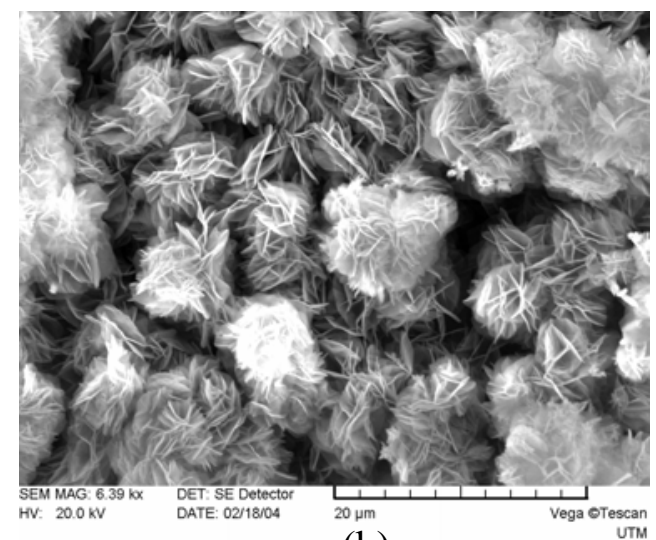

(b)

Figure 1. Top view SEM images of the $\mathrm{ZnO}$ nanostructures surfaces chemically deposited from (a) Zn:Sn:[DEN] (0.05 M:1 mM:0.02 M) aqueous bath; (b) (0.10 M:1 mM:0.01 M) aqueous bath on the glass substrate.

Figure 2 shows the ultraviolet emission photoluminescence (PL) spectra of $\mathrm{ZnO}: \mathrm{Sn}$ chemically deposited from Zn:Sn:[DEN] (0.05 M:1 mM: $0.02 \mathrm{M})$ aqueous bath and RPP annealed at temperature of $650^{\circ} \mathrm{C}$ for $20 \mathrm{~s}$. One can see that the emission from the as grown film represents a combination of luminescence dominated by a PL band associated with the recombination of excitons bound to a neutral donor $\left(\mathrm{D}^{0} \mathrm{X}\right)$ and resonant Raman scattering (RRS). The RPP leads to the suppression of PL and the enhancement of multiphonon RRS labeled as $2 \mathrm{LO}_{\mathrm{RRS}}-5 \mathrm{LO}_{\mathrm{RRS}}$ peaks. The difference between the

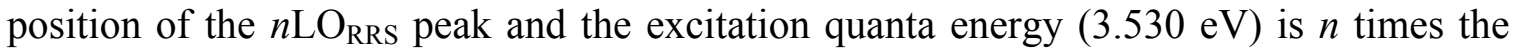
energy of the $\mathrm{A}_{1}(\mathrm{LO})$ phonon in wurtzite-type $\mathrm{ZnO}(72 \mathrm{meV})$. It means that this emission originates from the $n$-order Raman scattering. Resonant Raman scattering from solids can be observed if the energy of the incoming or scattered photons matches real electronic states in the material (15).

The luminescence peak in the as grown film $(3.363 \mathrm{eV})$ is close to the previously reported $\mathrm{I}_{4}$ line (16) associated with excitons bound to a H-related neutral donor. It could be that our layers are unintentionally doped with hydrogen. Another possibility is that the 


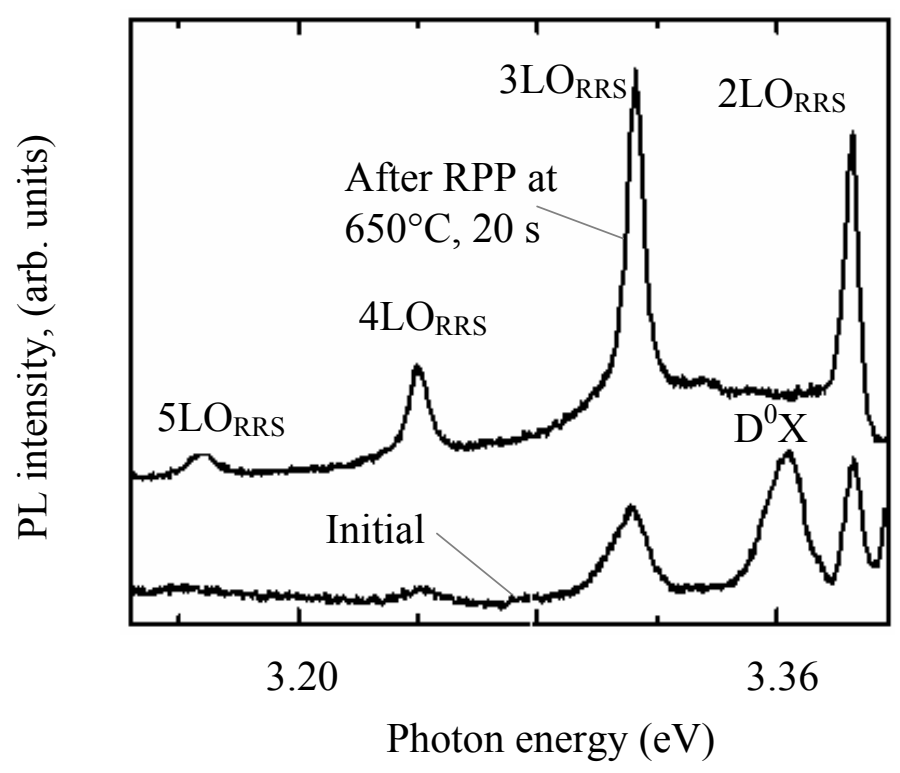

Figure 2. Ultraviolet emission spectra of different $\mathrm{ZnO}$ nanocomposite fabricated by chemical deposition and rapid photothermal processing at $650^{\circ} \mathrm{C}$ for $20 \mathrm{~s}$, and measured at $10 \mathrm{~K}$. The spectra are shifted vertically for clarity.

$\mathrm{D}^{0} \mathrm{X}$ PL band in our samples is related to an exciton bound to some structural defects. In such a case, the suppression of the $\mathrm{D}^{0} \mathrm{X}$ PL band with increasing the RPP is explained by the annealing of defects which localize the excitons. Figure 3 shows the visible PL emission spectra of the as-grown sample and the processed sample using RPP at $650^{\circ} \mathrm{C}$ for $20 \mathrm{~s}$. Apart from this $\mathrm{D}^{0} \mathrm{X}$ UV luminescence, two PL bands centered at 2.4 and $1.8 \mathrm{eV}$ are present in the visible spectral range as illustrated in Fig. 3. The PL spectra of the asgrown film show a typical green-red deep-defect level emission at $1.8 \mathrm{eV}$ without nearband edge emission. The visible luminescence is also strongly suppressed by increasing the RPP temperature. The RPP at temperatures $650^{\circ} \mathrm{C}$ for $20 \mathrm{~s}$ decreased the intensity of the red PL $(1.8 \mathrm{eV})$ luminescence.

One can see that the emission from the as grown film represents a combination of luminescence dominated by a PL band associated with the recombination of excitons bound to a neutral donor $\left(\mathrm{D}^{0} \mathrm{X}\right)$ and resonant Raman scattering (RRS). Deep-defect-level emission is essentially reduced and newly emerging near-band edge emission is improved in the $\mathrm{ZnO}$ RPP annealed at the $650{ }^{\circ} \mathrm{C}$.

The $\mathrm{ZnO}$ nanostructured thin film annealed at $650{ }^{\circ} \mathrm{C}$ shows a near-band edge emission at $3.38 \mathrm{eV}$ and much lower emission peak related to deep-defect-level. The reduction of deep-defect-level emission in the rapid photothermal processed $\mathrm{ZnO}$ indicates that the concentration of defects responsible for the deep-defect-level emission is reduced by RPP (17). 


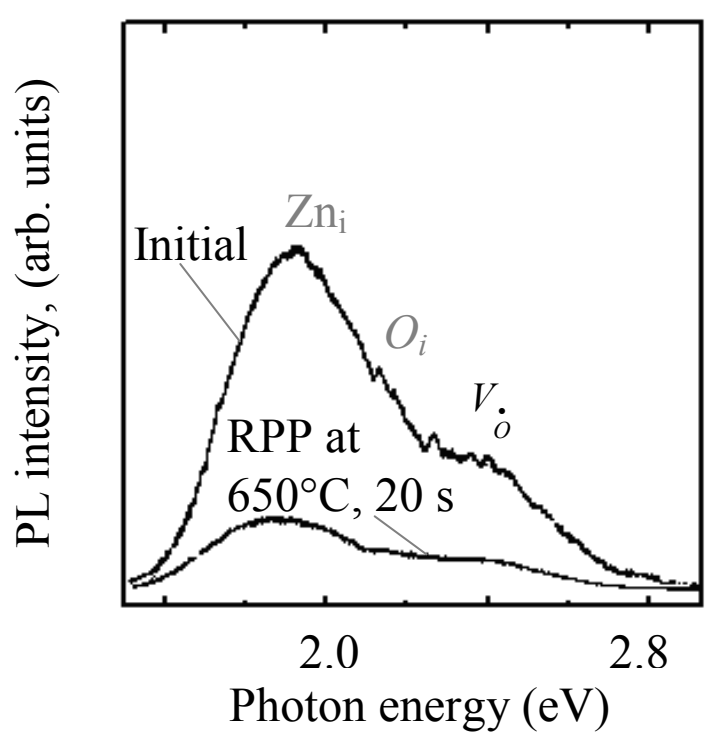

Figure 3. Visible PL spectra of $\mathrm{ZnO}$ nanostructured films as labeled: Initial is the asgrown film and second is treated by RPP at $650{ }^{\circ} \mathrm{C}$ for $20 \mathrm{~s}$, and measured at $\mathrm{T}=10 \mathrm{~K}$.

It was observed that irreversible changes in the PL occurs when the $\mathrm{ZnO}$ films were post-growth rapid photothermal processed at temperatures higher than $300{ }^{\circ} \mathrm{C}$ for $20 \mathrm{~s}$. In the temperature range $550-650^{\circ} \mathrm{C}$, it was observed that improvement of the quality and stability of the $\mathrm{ZnO}$ samples occurs (13). Reliable ohmic contacts can be made to the $\mathrm{ZnO}$ without much difficulty by vacuum evaporation of $\mathrm{Al}$.

For gas sensing characterization, a $1000 \mathrm{cc}$ gas chamber was used. The porosity of the nanostructured $\mathrm{ZnO}$ thin films were not measured. The undoped, and Sn-doped zinc oxide thin films $(0.3 \mathrm{~cm} \times 0.3 \mathrm{~cm} \times 1 \mu \mathrm{m})$ were used as sensor elements to detect methanol and ammonia at temperatures from 20 to $300^{\circ} \mathrm{C}$ with a concentrations range 0 $100 \mathrm{ppm}$. The readings were taken $20 \mathrm{~min}$ after the gases have been introduced in the test chamber. It was found that resistance change $\Delta R=\left|R_{\text {gas }}-R_{\text {air }}\right|$ increased linearly with gas concentration. The sensitivity of the sensor element to gases was calculated according to the formula $(10,14)$ :

$$
S=\frac{100 \cdot \Delta R}{C \cdot R_{\text {air }}}=\frac{100 \cdot\left(\left|R_{\text {gas }}-R_{\text {air }}\right|\right)}{C \cdot R_{\text {air }}}
$$

where $C$ is the gas concentration, $R_{\text {gas }}$ and $R_{\text {air }}$ are the electrical resistance of the sensor element in the presence of gas and in air, respectively.

The sensitivities of the $\mathrm{ZnO}$ and $\mathrm{ZnO}: \mathrm{Sn}$ thin films to $100 \mathrm{ppm}$ ammonia in air are shown in Figure 4 at a working temperature of $100{ }^{\circ} \mathrm{C}$ and a relative humidity $(\mathrm{RH})$ of $40 \%$. It was observed that the sensitivity increased with increased RPP temperature and reached a maximum at about $650^{\circ} \mathrm{C}$ for detecting $\mathrm{NH}_{3}$. However for elements that were RPP processed below $400^{\circ} \mathrm{C}, 20 \mathrm{~s}$, the resistivity was not restored to the original level within $60 \mathrm{~min}$. Therefore, a RPP temperature in the range $550-650^{\circ} \mathrm{C}$ for $20 \mathrm{~s}$ was desirable. 
Figure 4 shows the response kinetics of sensor elements annealed by RPP to $100 \mathrm{ppm}$ concentration of ammonia pulse at a working temperature of $100{ }^{\circ} \mathrm{C}$ and $40 \% \mathrm{RH}$. The adsorption and desorption processes can take place quickly in the annealed sample, but the necessary time for the saturation of the resistivity value is different for the adsorption and desorption processes. The results for zinc oxide samples rapid photothermal processed at temperatures below $600{ }^{\circ} \mathrm{C}$ is omitted due to fluctuation of the response in these sensor elements.

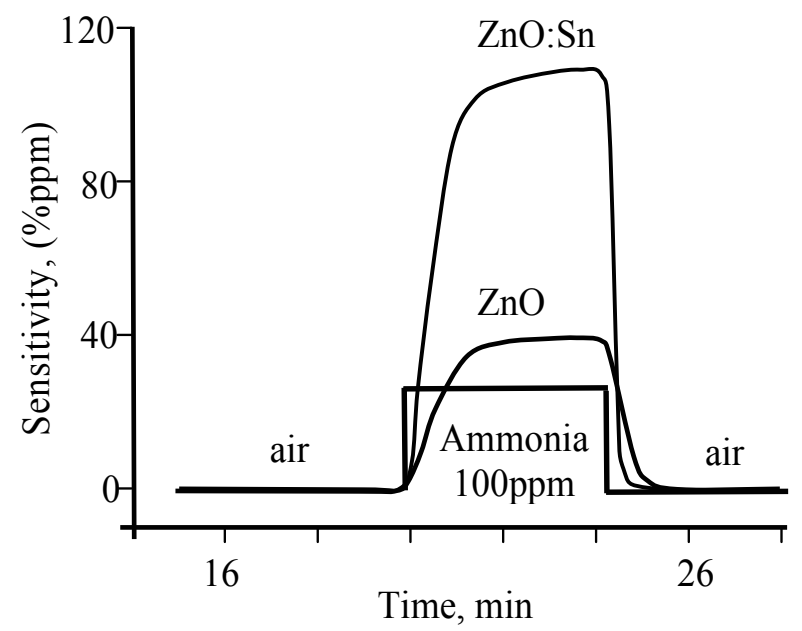

Figure 4. The response of the $\mathrm{ZnO} \& \mathrm{ZnO}: \mathrm{Sn}$ nanostructured thin film sensor to ammonia at a working temperature of $100{ }^{\circ} \mathrm{C}$ and $40 \% \mathrm{RH}$.

The $\mathrm{NH}_{3}$ sensing characteristics of sensors were performed at a working temperature of $100{ }^{\circ} \mathrm{C}$ and $40 \% \mathrm{RH}$. Figure 4 shows that sensor response and recovery time constants are of the order of $30 \mathrm{sec}$, and there is a complete stabilization after $60 \mathrm{sec}$. The conductivity decreased rapidly by exposing the sensor to ammonia, and recovered toward the original value after introducing clean air. This demonstrates a high potential for nanostructured metal oxide sensors with superior sensitivity.

\section{Conclusion}

In this study, the novel nanostructured zinc oxide films were fabricated by chemical deposition and rapid photothermal processing and were demonstrated to be a good gas sensor for ammonia. It was observed that undoped $\mathrm{ZnO}$ thin films have a very low sensing response towards $\mathrm{NH}_{3}$. The gas sensing characteristics of the $\mathrm{ZnO}$ films can be improved by introducing $\mathrm{Sn}$ dopants into the nanostructured $\mathrm{ZnO}$ thin films. Further investigations with different dopants and second components in $\mathrm{ZnO}$ thin films are underway.

\section{Acknowledgements}

We would like to thank the help of Prof. Dr.hab. I. Tigineanu, Dr.hab. V.Ursaki Academy of Sciences of Moldova and Mr. Monaico E., National Center for Materials Study and Testing, for the photoluminescence, SEM, EDX analyses and discussions. Financial supports by the MRDA-CRDF project MOE2-3052-CS-03 and by the Ministry of Education and Science of Republic of Moldova through the Project 321b/s are gratefully acknowledged. 


\section{References}

1. J. Y. Lao, J. Y. Huang, D. Z. Wang, Z. F. Ren, D. Steeves, B. Kimball, and W. Poter, Appl. Phys. A Materials Science \& Processing, 78, 539 (2004); P. X. Gao and Z. L. Wang, Journal of Applied Physics, 97, 044304 (2005).

2. O. K. Varghese and C. A. Grimes, Journal of Nanoscience and Nanotechnology, 3, 277 (2003).

3. H. J. Fan, W. Lee, R. Scholz, A. Dadgar, A. Krost, K.Nielsch, and M. Zacharias, Nanotechnology, 16, 913 (2005).

4. Y. Xia, P. Yang, Y. Sun, Y. Wu, B. Mayers, B. Gates, Y. Yin, F. Kim, and H. Yan, Adv. Mater. 15, 353 (2003).

5. K. Hara, T. Horiguchi, T. Kinoshita, K. Sayama, H. Sugihara, and H. Arakawa, Sol. Energy Mater. Sol. Cells, 64, 115 (2000).

6. Sang Choon Ko, Yong Chul Kim, Seung Seob Lee, Seung Ho Choi and Sang Ryong Kim, Sensors and Actuators A: Physical, 103, 130 (2003).

7. Joo-Hwan Han and Doh-Yeon Kim, Journal of the European Ceramic Society, 18, 765 (1998).

8. Soo-Hyung Seo, Wan-Chul Shin and Jin-Seok Park, Thin Solid Films, 416, 190 (2002).

9. G.Sberveglieri, S.Groppelli, P.Nelli, A.Tintinelli and G.Giunta, Sens. Actuat. B, 25, 588 (1995).

10. S. T. Shishiyanu, T. S. Shishiyanu, O. I. Lupan, Sens. Actuat. B, 107, 379 (2005).

11. R. Singh, M. Fakhruddin, and K. F. Poole, Applied Surf. Sci., 168, 198 (2000).

12. I. O. Oladeji and L. Chow, J. Electrochem. Soc., 144, 2342 (1997).

13. S. Shishiyanu, O. Lupan, E. Monaico, V. Ursaki, T. Shishiyanu, and I. Tiginyanu, Thin Solid Films, 488, 15 (2005).

14. O. Lupan, Technology of oxides $\mathrm{ZnO}, \mathrm{Cu}_{2} \mathrm{O}$, $\mathrm{SiO}_{2}$ obtaining with rapid photon annealing for semiconductor devices. Ph.D. Dissertation, Chisinau, Moldova, 2005, 152p.

15. P. Y. $\mathrm{Yu}$ and M. Cardona, Fundamentals of Semiconductors, Berlin/Heidelberg/New York, Springer-Verlag, (1996).

16. B. K. Meyer, H. Alves, D. M. Hofmann, W. Kriegseis, D. Forster, F. Bertram, J. Christen, A. Hoffmann, M. Strassburg, M. Dwworzak, U. Haboeck, and A.V. Rodina, Phys. Status Solidi B, 241, 231 (2004).

17. S. Shishiyanu, R. Singh, T. Shishiyanu, O. Lupan, Impact of Rapid Photothermal Processing on Properties of $\mathrm{ZnO}$ Nanostructures for Solar Cell Applications, $25^{\text {th }}$ International Conference on Microelectronics-MIEL, Belgrade, Serbia and Montenegro, ISBN: 1-4244-0117-8, p.153-156, 14-17 May (2006). 